\title{
Local Context Influence, Activity Space, and Foodscape Exposure in Two Canadian Metropolitan Settings: Is Daily Mobility Exposure Associated with Overweight?
}

\author{
Alexandre Lebel, ${ }^{1,2}$ Yan Kestens, ${ }^{2}$ Robert Pampalon, ${ }^{3}$ Marius Thériault, ${ }^{4}$ \\ Mark Daniel, ${ }^{5,6}$ and S. V. Subramanian ${ }^{1}$ \\ ${ }^{1}$ Harvard School of Public Health, 677 Huntington Avenue, Boston, MA 02215, USA \\ ${ }^{2}$ Centre Hospitalier de l'Université de Montréal, 3850 Saint-Urbain Street, Montréal, QC, Canada H2W 1T7 \\ ${ }^{3}$ Institut National de Santé Publique du Québec, 945 Avenue Wolfe, Québec, QC, Canada G1V 5B3 \\ ${ }^{4}$ Centre for Research in Regional Planning and Development, Laval University, FAS-1616, 2325 Rue Bibliothèques, \\ Quebec, QC, Canada G1V 0A6 \\ ${ }^{5}$ Sansom Institute for Health Research, University of South Australia, G.P.O. Box 2471, Adelaide, SA 5001, Australia \\ ${ }^{6}$ Department of Medicine, St. Vincent's Hospital, The University of Melbourne, 41 Victoria Parade, Fitzroy, VIC 3065, Australia
}

Correspondence should be addressed to Alexandre Lebel, alebel@hsph.harvard.edu

Received 1 September 2011; Revised 28 October 2011; Accepted 12 November 2011

Academic Editor: Douglas Thompson

Copyright (C) 2012 Alexandre Lebel et al. This is an open access article distributed under the Creative Commons Attribution License, which permits unrestricted use, distribution, and reproduction in any medium, provided the original work is properly cited.

It has become increasingly common to attribute part of the obesity epidemic to changes in the environment. Identification of a clear and obvious role for contextual risk factors has not yet been demonstrated. The objectives of this study were to explain differences in local overweight risk in two different urban settings and to explore sex-specific associations with estimated mobility patterns. Overweight was modeled within a multilevel framework using built environmental and socioeconomic contextual indicators and individual-level estimates of activity space exposure to fast-food restaurants (or exposure to visited places). Significant variations in local levels in overweight risk were observed. Physical and socioeconomic contexts explained more area-level differences in overweight among men than among women and among inhabitants of Montreal than among inhabitants of Quebec City. Estimated activity space exposure to fast-food outlets was significantly associated with overweight for men in Montreal. Locallevel analyses are required to improve our understanding of contextual influences on obesity, including multiple influences in people's daily geographies.

\section{Introduction}

The obesity epidemic has been recognized as a major public health problem for over a decade [1]. Obesity has a substantial negative effect on longevity, reducing the lifespan of severely affected people by 5 to 20 years [2]. At the individual level, traditional explanations of obesity rely on three factors: metabolism, diet, and physical inactivity. In turn, these factors are influenced by genetic traits [3]. Genetics influences the individual predisposition but cannot directly explain the important increase in the prevalence of obesity prevalence over the past decades [3-5]. At the population level, this impact on life expectancy has important public policy implications [6]. In industrialized nations, groups with lower socioeconomic status (SES) are generally at greater risk of becoming obese. This is so particularly among women, for whom findings are relatively consistent [7]. Many studies controlling for individual SES also report an association between measures of the social or physical context and obesity $[8,9]$. While it is theoretically sound and increasingly common in the published literature to attribute the obesity epidemic, in part, to changes in environmental context [10], current empirical evidence does not identify a clear and obvious role for contextual risk factors. There is an absence of agreement on how the built and social contexts should be measured and modeled, as well as the geographic scale at 
which local area studies should be done [10, 11]. Exposure to fast-food restaurants has been hypothesised to be a substantial influence on individuals' diet [12], but its association with overweight/obesity is unclear [13].

Many authors suggest further explorations at a local geographic scale in order to increase our understanding of contextual influences on obesity [14]. Indeed, the geographies of obesity/overweight appear to be more complex than might be interpreted from previous evidence [11]. Many literature reviews confirm the irregularity of associations between environmental indicators and weight-related outcomes (BMI, overweight, or obesity) [9, 13, 15-17]. An additional recommendation to resolve ambiguities in the role of contextual factors is to account for daily mobility patterns in analyses $[14,15,18]$, as opposed to measurement based on residential location, in order to evaluate individuals' activityspace exposure to food environments [16] and, thus, not succumb to the "local or residential trap" $[19,20]$, that is, not considering environmental influences other than those located around one's residence [18].

In Canada's Province of Quebec, significant differences in overweight (BMI $\geq 25 \mathrm{~kg} / \mathrm{m}^{2}$ ) have been reported at the regional level after controlling for individual SES and lifestyle factors [21]. The differentials in variance between regions suggest that contextual influences might vary between regions and genders [22]. Put differently, these studies suggest that the level of influence of regional characteristics might vary between settings as well as between men and women.

The main objective of this study was to explore associations between a variety of contextual characteristics and the likelihood of being overweight in two urban settings, Montreal and Quebec City, and also to assess variation between men and women. Specifically, we aimed to (1) describe regional and sex-specific associations between overweight and contextual indicators of socioeconomic status, built environments and fast-food outlet exposure, and (2) compare associations obtained for a local residential-based indicator of fastfood exposure and an alternate measure based on individuals' activity space exposure, to evaluate whether accounting for daily mobility increases the strength of the association between fast-food outlet exposure and overweight.

\section{Methods}

Study Areas. This study compares the two urban areas of Montreal Island and Quebec City (Table 1). The former is the core of the largest metropolitan area of the province and is an important port-of-entry for immigration to Canada. It is culturally mixed, and its urban design characteristics vary considerably across neighborhoods [23]. The latter is the second largest metropolitan area of the province and is culturally very homogeneous. Quebec City also has a relative important variety in its urban design across neighborhoods but is among the Canadian cities with the highest ratio of highway kilometres per capita [24], estimated at 2.75 times Montreal's rate (Table 1). Both cities importantly differ in their urban structure: the classic monocentric model applies to Montreal, whereas Quebec City follows an axial pattern in land use due to historical and topographical reasons [25].
Both regions contain administrative geographical units consistent with notions of "neighborhood" and suitable for multilevel analyses [26]. In 2007, the Montreal Public Health Department purposely defined 111 geographic units covering the entire island of Montreal to shape interventions at the local level. Local stakeholders involved in the creation process characterized these units as natural sociologic areas [27]. These units are nested in turn within larger areas of local health and social services $(n=29)$ which were used as second-level units for nested analyses. In Quebec City, the 38 local units used in this analysis include the 36 official neighbourhoods of the city (2008), historically defined by city planners and citizens, and two additional units consisting of small peripheral areas (suburbs) located to the east (shore) and north of the city (mountains) of the city. These units all comprise an integer number of census dissemination areas from which selected contextual characteristics were drawn from the 2001 Canada census.

2.1. Data. Cycles 2.1 and 3.1 of the Canadian Community Health Survey (CCHS 2003, 2005) were combined for analyses. The Canadian Community Health Survey is a representative nationwide survey that collects individuals' socioeconomic and health-related information at the sub-provincial level from the year 2000. It relies on a large sample of respondents (approximately 130,000 per cycle), is designed to provide reliable estimates at the health region level, and has the central objective of supporting health-surveillance programs and public-health research [28]. Weights accounting for the sample plan, gender, and health region were used.

2.2. Outcome Variable. The outcome variable was a dichotomous indicator of overweight (BMI $\geq 25 \mathrm{~kg} / \mathrm{m}^{2}$ ) computed from self-reported height and weight provided by CCHS participants [1]. Underweight individuals (BMI $\leq 18.5)$ were removed from the sample in order to compare normalweight individuals with those at risk for overweight-related diseases.

2.3. Individual-Level Variables. Table 1 summarizes information about SES and lifestyle for non-pregnant adults $(\geq 18$ year old) of studied areas. Individuals with missing information were discarded from the analysis except for those missing income. Due to a relatively high occurrence of missing data $(13 \%)$ on individuals' available income, a missing income variable was created.

We built an indicator estimating a respondent's exposure to fast-food restaurants based on the mobility patterns of travel-survey participants within the same territory. Computation of these variables is complex; a detailed description of the procedure is available elsewhere [18]. In summary, the creation of this estimated "activity space foodscape" (E-ASF) relies on a multiple-regression model using activity-location data from a travel-survey (Origin-destination survey 2003 in Montreal and 2001 in Quebec City) and a geocoded business registry (Tamec businesses registry 2003-2004). Kernel densities of fast-food restaurants and of all restaurants were computed for each city (geographic raster of $100 \mathrm{~m}^{2}$ 
TABLE 1: Descriptive statistics for the Island of Montreal and Quebec City area.

\begin{tabular}{|c|c|c|c|}
\hline & & Montreal & Quebec \\
\hline \multirow{6}{*}{ Study Area } & Population $(2001)^{\mathrm{a}}$ & 1845137 & 564277 \\
\hline & CCHS sample & 3244 & 2334 \\
\hline & Average sample size by local area (neighbourhood) & 112 & 71 \\
\hline & $\%$ of French as maternal language ${ }^{\mathrm{a}}$ & 51.1 & 95.8 \\
\hline & $\%$ of visible minority ${ }^{\mathrm{a}}$ & 21.1 & 1.8 \\
\hline & Highway km per 10000 pers. $^{\mathrm{a}-\mathrm{b}}$ & 2.44 & 6.71 \\
\hline \multirow{15}{*}{ Individual } & & \multicolumn{2}{|c|}{$\%$} \\
\hline & Overweight (BMI $\geq 25)$ & 45.4 & 43.8 \\
\hline & Obese $(\mathrm{BMI} \geq 30)$ & 14.2 & 12.1 \\
\hline & Gender (men) & 47.3 & 43.6 \\
\hline & 18-24 years old & 12.1 & 13.8 \\
\hline & $25-44$ years old & 40.2 & 35.3 \\
\hline & 45-64 years old & 31.2 & 35.9 \\
\hline & Over 65 years old & 16.5 & 15.0 \\
\hline & No high school diploma & 20.0 & 14.5 \\
\hline & High school of college diploma & 50.9 & 62.1 \\
\hline & University degree & 29.1 & 23.4 \\
\hline & Available income-low* & 27.8 & 20.9 \\
\hline & Available income-high & 59.9 & 65.9 \\
\hline & Missing income & 12.3 & 13.2 \\
\hline & Average $\%$ fast-food (E-ASF-) ${ }^{c}$ & 18.7 & 33.0 \\
\hline \multirow{12}{*}{ Neighbourhood } & Average $\%$ immigrant $^{\mathrm{a}}$ & 27.1 & 3.5 \\
\hline & Average $\%$ of single ${ }^{a}$ & 44.1 & 45.1 \\
\hline & Average $\%$ of less than 13 years of schooling ${ }^{\mathrm{a}}$ & 15.7 & 11.8 \\
\hline & Average $\%$ who moved within the last year ${ }^{\mathrm{a}}$ & 16.8 & 14.9 \\
\hline & Average $\%$ of single parent households ${ }^{\mathrm{a}}$ & 21.8 & 18.0 \\
\hline & Average median income $(\mathrm{CAN} \$)^{\mathrm{a}}$ & 37676 & 43138 \\
\hline & Average dwelling density $\left(\mathrm{km}^{2}\right)^{\mathrm{a}}$ & 2751 & 1289 \\
\hline & Average $\%$ of dwellings constructed before $1946^{a}$ & 21.5 & 13.4 \\
\hline & Avegage motorisation rate ${ }^{c}$ & 72.2 & 73.8 \\
\hline & Average number of four-way intersections (connectivity) ${ }^{\mathrm{b}}$ & 26.4 & 16.1 \\
\hline & Average land use mix score $(100=\text { equal land use; } 0=\text { single land use })^{\mathrm{b}}$ & 76.8 & 53.5 \\
\hline & Average $\%$ fast-food $(\mathrm{O}-\mathrm{NF}-)^{\mathrm{c}}$ & 20.2 & 38.6 \\
\hline
\end{tabular}

Sources: CCHS 2003-2005 or a: Statistics Canada 2001; b: source DMTI Spatial 2005; c: Tamec businesses registry 2003-2004, OD survey 2001(Qc)-2003(Mtl), and CCHS 2003-2005.

* Less than $30 \mathrm{~K} \$$ for household of 1 or 2 individuals; less than $40 \mathrm{~K} \$$ for 3-4 individuals; less than $60 \mathrm{~K} \$$ for 5 individuals or more.

cells) thus transforming point data (restaurants) into a spatial continuum reflecting restaurants density unconstrained by neighborhood boundaries. Destinations of travel-survey participants were mapped above this continuum in order to estimate individuals' activity-space exposure to both kinds of restaurant. The index was constructed from individual information (age, gender, occupation, household type, household size) and local-area residential characteristics computed at the census tract level (street connectivity, motor-vehicle ownership rate, density of buildings constructed before 1946, education level, and immigration rate). This procedure was done separately for fast-food restaurants and for all restaurants (including fast-foods) to provide an estimate of density at any location. In order to provide an indication on the "relative availability" of fast-food restaurants, we further computed the proportion of fast-food restaurants on the density of all restaurants. This relative index was preferred to an absolute value of density since it provides a better approximation of the foodscape, that is, the food establishments' idiosyncrasy for a given area. For example, two individuals could be living in areas presenting the same density of fast-food outlets-say, 10 outlets per square kilometerbut in one case these could represent all available restaurants in the area (100\% of restaurants are fast food outlets), and in the other case these could represent a fraction of all restaurants available. In such a scenario, even if fast-food outlet densities were equal in both places, one could argue that the person with no alternative would experience a higher (relative) exposure to fast-food outlets.

Separate models were calibrated for Montreal and for Quebec City to predict exposure to the proportion of fastfood outlet density. These models were then applied to the 
CCHS participants to establish the actual E-ASF measures. In the context of this study, we used the E-ASF variable to estimate the proportion of fast-food restaurants to which an individual is exposed in his or her activity space, for a typical weekday.

2.4. Contextual Variables. Four contextual variables were computed for both settings at the local area (neighborhood) level (Tables 1 and 2). The objective neighborhood exposure to foodscape (O-NF) measure was based on the same information as the E-ASF indicator but differed in its spatial structure. It is a direct measure of the proportion of restaurants classified as fast-food restaurants [18] relative to all restaurants within a local unit.

The three other contextual variables were constructed based on a series of socioeconomic indicators (Canadian census 2001), built environment indicators (DMTI Spatial, 2005), and motor-vehicle ownership rate (origin-destination sur-veys). We conducted principal component analyses (PCAs) separately for each region (Montreal and Quebec), on each subset of variables. This procedure allows for including synthesized information on a series of correlated variables, with resulting PCA factors presenting uncorrelated indicator [29]. To allow comparability and give independence to the measurement scale, each indicator $\left(x_{c}\right)$ was centered on the mean and reduced by its standard deviation, as shown in (1):

$$
x_{c}=\frac{(x-\mu)}{\sigma} \text {. }
$$

2.5. Statistical Analyses. Multilevel modeling is regularly used to study the role of context on the prevalence of obesity and other health disparities because it allows for the assessment of variation in health across small areas as a function of both composition (characteristics of the individuals within areas) and context (characteristics of the areas themselves), thus taking into account the dependent nature of individual observations within a specific area [30]. Multilevel logistic regressions were used to investigate relations between individual and contextual indicators and overweight [31]. A three-step procedure was performed to evaluate (1) the contribution of each contextual indicator and the ASF estimates on the individual's odds of being overweight as well as (2) the level-2 variance, given here as the magnitude of the territorial variance of overweight. All models control for survey cycle.

The first step simply enabled estimating whether there was a significant $(P<0.05)$ territorial variation of overweight where $\beta_{0}$ is the overall mean probability expressed on the logistic scale and is the area-level residual, no covariates included (null model, formula (2)):

$$
\log i t\left(\pi_{i j}\right)=\beta_{0}+u_{0 j}
$$

In the second step we added individual socioeconomic and demographic variables: age, education level, and available income (SES model, formula (3)):

$$
\log i t\left(\pi_{i j}\right)=\beta_{0}+\beta_{n} x_{i j}+u_{0 j}
$$

This allows to estimate the second-level variance not explained by individual characteristics. The third step individually presents the strength of association for each contextual indicator and the ASF estimate as well as the remaining level2 variance not explained by the complete model (Formula (4)), where the logit of the probability $\pi$ of individual $i$ in neighbourhood $j$ is the sum of (1) the city-wide probability of being overweight $\left(\beta_{0}\right)$, (2) the adjustment of $n$ variables at individual level $\left(\beta_{n} x_{i j}\right)$, (3) the selected variable at the second level $\left(\beta_{1} x_{0 j}\right)$, and (4) the neighbourhood-specific differential of overweight probability $\left(u_{0 j}\right)$. This last parameter is important as analysis of its variance $\left(\sigma^{2} u_{0}\right)$ contributes to the interpretation of the contextual effect:

$$
\log i t\left(\pi_{i j}\right)=\beta_{0}+\beta_{n} x_{i j}+\beta_{1} x_{0 j}+u_{0 j}
$$

We then estimated the proportion of the removed variance (RV) at the second level by adding one contextual variable. This is done by separately adding each contextual variable to the individual SES model, and then computing the proportion of the level-2 variance, this specific variable removes from the SES model (formula (5)). Since the Social Diversity and Financial Insecurity (socioeconomic factors) derive from the same PCA, they were kept in the same model:

$$
\mathrm{RV}=\frac{\left(\sigma^{2} u_{0} \mathrm{SES}\right)-\left(\sigma^{2} u_{0} \text { context }\right)}{\sigma^{2} u_{0} \mathrm{SES}}
$$

All regressions were estimated using the residual-iterated generalized least squares (RIGLSs) and the predictive quasilikelihood (PQL) in MlwiN 2.17.

\section{Results}

Table 2 summarizes the PCA loading scores after Varimax rotation (read as a correlation coefficient). Although Montreal and Quebec City have different general characteristics, the same three components emerge from PCAs independently conducted in both cities. Subsequent parameter differences observed in the modeling of overweight cannot consequently be attributed to heterogeneity of these factors between cities. The PCA run on the socioeconomic indicators resulted in two factors (Eigenvalue $>1$ ). The first factor, labeled Social Diversity, was mainly correlated with the proportion of people living alone and the proportion of recent movers. The second factor-Financial Insecurity-was correlated with the proportion of people with low education, a single parent households, and median area income. The third factor came from the PCA run on the built environment variables. Labeled Centrality, referring to urban city center structure, this factor was mainly correlated with the percentage of dwellings built before 1946, the dwelling density, the average rate of motor-vehicle ownership by household, and street-network connectivity.

Multilevel logistic regressions were then conducted independently for men and women in Montreal and Quebec City. Table 3 summarizes results for the three-step procedure for both cities and genders. The empty models indicated a larger significant area-level variance $\left(\sigma^{2} u_{0}\right)$ in Montreal for both 
TABle 2: Principal components loadings for the socioeconomic and physical environments in Montreal and Quebec City.

\begin{tabular}{|c|c|c|c|c|c|c|c|}
\hline \multirow[t]{2}{*}{ Area-level indicators } & & \multicolumn{2}{|c|}{ Social diversity } & \multicolumn{2}{|c|}{ Financial insecurity } & \multicolumn{2}{|c|}{ Centrality } \\
\hline & & Montreal & Quebec & Montreal & Quebec & Montreal & Quebec \\
\hline \multirow{5}{*}{ Socioeconomic environment } & $\%$ singles & 0.955 & 0.941 & 0.129 & 0.137 & - & - \\
\hline & $\% 1$ year mover & 0.968 & 0.949 & 0.117 & 0.187 & - & - \\
\hline & $\%$ less schooling & -0.218 & -0.03 & 0.947 & 0.976 & - & - \\
\hline & $\%$ single parents & 0.442 & 0.533 & 0.808 & 0.775 & - & - \\
\hline & Median income & -0.487 & -0.62 & -0.824 & -0.73 & - & - \\
\hline \multirow{5}{*}{ Physical environment } & \% old dwelling & - & - & - & - & 0.844 & 0.820 \\
\hline & Dwellings density & - & - & - & - & 0.908 & 0.904 \\
\hline & Motorisation rate & - & - & - & - & -0.958 & -0.98 \\
\hline & Con nectivity & - & - & - & - & 0.935 & 0.933 \\
\hline & Land use mix & - & - & - & - & 0.069 & 0.532 \\
\hline
\end{tabular}

men and women. In Quebec, the effect was slightly lower among women, whereas no significant territorial difference in overweight was observed among men. Models including SES variables (Step 2) indicated associations between overweight and age, education, and income for both men and women. The area-level variance fell substantially for men and women in Montreal. Step 3 presents the associations for the four contextual indicators as well as the E-ASF for fastfood density in a series of four models. This step allows the direct comparison of two sets of information: the indicators' relative strength with the odds of being overweight (OR) and their contribution to explaining the magnitude of the territorial variations. All these models hold the individual SES constant (Step 2).

3.1. Indicators' Relative Strength. Except for the Financial Insecurity factor, all indicators were significantly associated with overweight among men in Montreal. The strongest associations were observed for social diversity, where an increase of 1 standard deviation reduced the odds of being overweight by $35 \%(\mathrm{OR}=0.74)$ and the neighborhood-based fast-food proportion measure $(\mathrm{OR}=1.34)$. The ASF, which estimates one's fast-food exposure according to personal mobility, was slightly less strongly associated than the $\mathrm{O}$ NF. Associations found for women in Montreal tended to be weaker, and the activity-space-based fast-food density indicator was not significant. For women in Quebec City, only Financial Insecurity and the proportion of fast-food restaurants in the neighbourhood significantly predicted the odds of being overweight. Although no territorial variance was detected for men in Quebec City, the Centrality factor was significantly associated with overweight.

3.2. Territorial Variations Magnitude. The RV index presented in Table 4 indicates the percentage of the territorial variation (area-level variance) explained by the addition of a specific contextual indicator to the SES model. It varies importantly between cities and between men and women.

In Montreal, all level-2 indicators having a significant association with overweight explained an important component of territorial variation in overweight, ranging from $37 \%$ to $48 \%$ for men and from $25 \%$ to $35 \%$ for women, the most important influences being the O-NF and contextual SES, respectively, for both men and women. In Quebec, the explained variance was of a lesser magnitude. Fewer indicators associated with overweight together explained less than $25 \%$ of the territorial difference in women, whereas none of the variance was explained for men $(0 \%)$. The ASF indicator importantly explained territorial differences only for men in Montreal (37.4\%).

\section{Discussion}

The primary findings of this study are thus as follows (1) contextual influences on overweight vary significantly between the two urban regions surveyed, and (2) predicted activityspace-based fast-food exposures are significantly associated with overweight for some subgroups of the population but do not explain as much territorial variance as traditional residential-based neighborhood indicators.

With the exception of the male subsample in Quebec City, our models show relatively important and statistically significant territorial variations in the local-area odds of being overweight. This indicates that the prevalence of overweight is not equally distributed between territories except for men in Quebec. Accounting for individual-level SES, a large part of this variance was explained for Montreal but not for Quebec City, suggesting that Quebec City holds a more uniform population from the standpoint of SES.

Comparing the RV index for all models further reveals differences between regions (Table 4), confirming observations made for other Canadian studies that a contextual effect could also be found at the regional scale, above and beyond individual SES [32, 33]. Contextual variables explained a negligible component of the territorial influence in Quebec City, compared to that explained for Montreal. Among women in Quebec City, the most important factor was the proportion of fast-food restaurants in the neighborhood of residence which explained $22 \%$ of the variance. The same variable explained a similar proportion of the variance for women in Montreal (25\%). However, the proportion of fast-foods outlets in the neighborhood were the weakest of statistically significant influences. Centrality and social factors (Social Diversity and Financial Insecurity) 


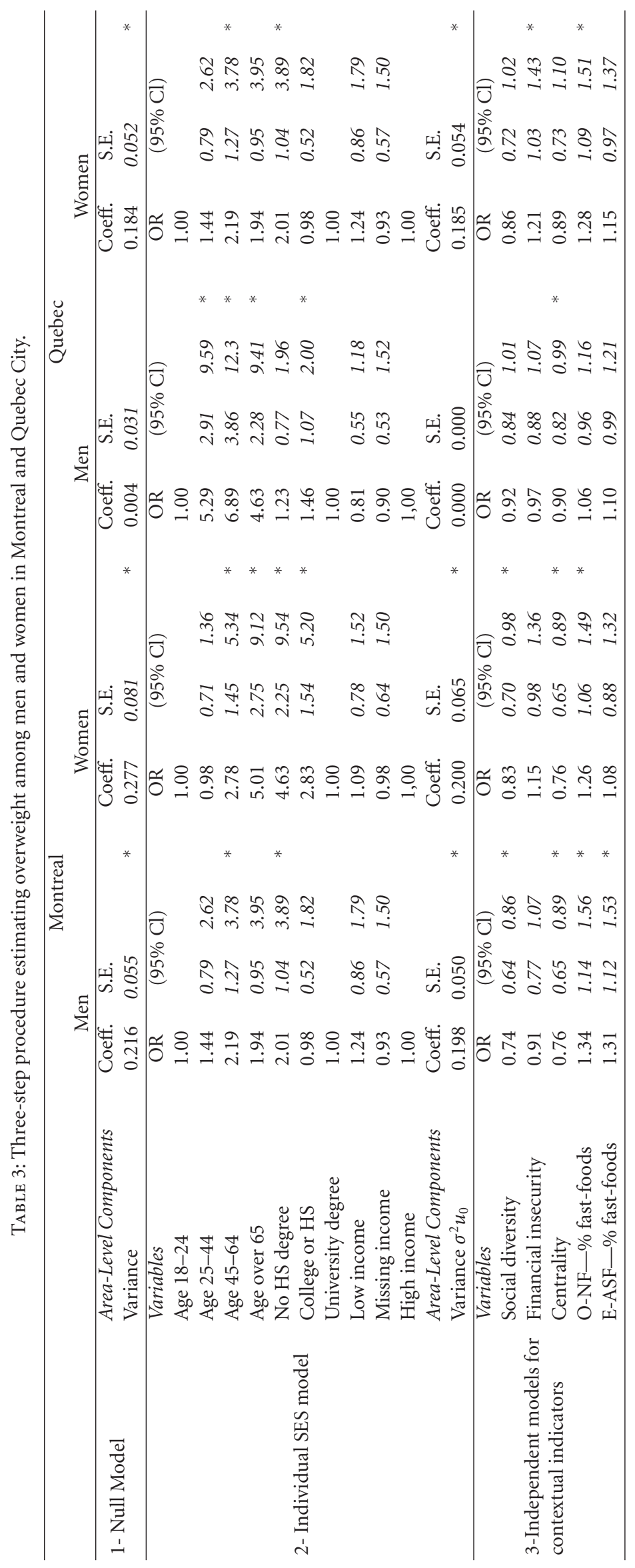


TABLE 4: Territorial variance of overweight for men and women in Montreal and Quebec City.

\begin{tabular}{|c|c|c|c|c|c|c|c|c|c|c|c|c|}
\hline \multirow{3}{*}{ Models } & \multicolumn{6}{|c|}{ Montreal } & \multicolumn{6}{|c|}{ Quebec } \\
\hline & \multicolumn{3}{|c|}{ Men } & \multicolumn{3}{|c|}{ Woman } & \multicolumn{3}{|c|}{ Men } & \multicolumn{3}{|c|}{ Woman } \\
\hline & Coeff. & S.E. & RV & Coeff. & S.E. & RV & Coeff. & S.E. & $\mathrm{RV}$ & Coeff. & S.E. & RV \\
\hline Individual SES & 0.198 & 0.05 & - & 0.200 & 0.066 & - & 0 & 0 & - & 0.185 & 0.054 & - \\
\hline Social factors & 0.118 & 0.029 & $40.4 \%$ & 0.130 & 0.056 & $35.0 \%$ & 0 & 0 & $0.0 \%$ & 0.160 & 0.049 & $14.0 \%$ \\
\hline Centrality & 0.118 & 0.035 & $40.4 \%$ & 0.131 & 0.047 & $34.5 \%$ & 0 & 0 & $0.0 \%$ & 0.190 & 0.053 & $-3.0 \%$ \\
\hline O-NF- $\%$ fast-foods & 0.104 & 0.034 & $47.5 \%$ & 0.150 & 0.052 & $25.0 \%$ & 0 & 0 & $0.0 \%$ & 0.144 & 0.045 & $22.0 \%$ \\
\hline E-ASF-\% fast-foods & 0.124 & 0.039 & $37.4 \%$ & 0.185 & 0.061 & $7.5 \%$ & 0 & 0 & $0.0 \%$ & 0.159 & 0.051 & $14.0 \%$ \\
\hline
\end{tabular}

RV: Removed level-2 Variance; O-NF: Objective Neighbourhood Foodscape; E-ASF: Estimated Activity Space Foodscape.

Social factors: social diversity and financial insecurity.

also explained a large part of the variance (up to $35 \%$ ). Contextual influences were definitely stronger for men in Montreal, where all contextual indicators explained over $40 \%$ of the territorial variance and reached $47.5 \%$ for the neighborhood proportion of fast-food outlets.

These observations indicate clear differences between Quebec City and Montreal. Whereas little between-area variance can be explained for Quebec City, almost 50\% can be explained for Montreal by the addition of only one contextual indicator. Exploratory analyses (not shown) that simultaneously included several factors indicated important multicolinearity. As a consequence, these associations need to be interpreted with care. Although each indicator appeared to be individually associated with overweight, all indicators explained a similar portion of the observed territorial variance. Accordingly, the factors used could all reflect a similar construct, linked to some elusive effect that could be termed the "socio-urban-foodscape." This interpretation is dependent on the importance of the variance; however, a small variance at the area level does not necessarily mean a small impact on the outcome. This can be observed, for example, when a strong effect is uniformly distributed between areas. A more in-depth study using different methodologies including qualitative methods would be useful in teasing apart observed differences between Montreal and Quebec City [34].

Another appealing observation concerned the E-ASF indicator (estimated activity space to foodscape). As opposed to the other indicators which were computed based on geographical boundaries, therefore referring to a specific territory, the E-ASF is more properly a spatial variable, distributed in space but not constrained by boundaries. This distinction is important because this indicator is computed with exactly the same geographical information as O-NF and differs only in how exposure and spatial structure are being considered. Although it contains geographical contextual information, the E-ASF is an individual indicator (level-1) and must be analysed accordingly.

The E-ASF proportion of fast-food restaurants was observed to be significantly associated with overweight in just one model. An increase in this exposure by one standard deviation yielded a $31 \%$ increase in the odds of overweight for men in Montreal and explained 37\% of the territorial variance observed. This suggests that exposures to multiple sites encountered during a single trip in an urban environment might influence overweightfor men in Montreal. This relationship was not apparent, however, for women, for whom where almost no territorial variance was explained by this indicator. Does this imply that men are more mobile than women and consequently more subject to destinations' characteristics? This is plausible, since other large studies observed that contextual effect on overweight is weaker among men than among women $[35,36]$. Consequently, visited places (or places to which one is exposed) during daily activities might be an important feature to consider in analyses modeling overweight. Once again, we must be careful in interpreting this exposure to fast-food restaurants, since the strength of association and the proportion of explained variance is similar to other factors, at least for men. Although individually based, it has a stronger association to overweight than contextual indicators. Future studies should specifically aim at untangling place-based and individual-based indicators such as the proportion of fast-food restaurant.

This paper suggests for Montreal and Quebec City that residential-area characteristics explain an important component of the territorial distribution of overweight, and that mobility patterns and related exposures to food environments are important features to consider for men. Associations might differ significantly between genders because their interaction with the environment could be of a different nature. Not considering the regional settings and gender differences would obscure such results.

This study has a number of limitations. The crosssectional design does not allow for the determination of causal effects. Although the CCHS offers individual-level health and lifestyle data of good quality, the self-reported information provided to derive the BMI and other indicators is subject to potential bias $[37,38]$. Also, as we did not have information on CCHS participants' mobility pattern, we used estimates of activity space exposure to foodscape. This procedure could yield an imprecise estimate for some subsamples and multicolinearity with other contextual variables. However, these estimates were calibrated using travel survey information and were done in the same geographic location where the CCHS sample was drawn. Such an approach may offer promising avenues for exploring the relationship between health status and activity space and could be tested in other cities with different spatial structures.

From an intervention standpoint, this study confirms the important role of the multidimensional reality of the local context and also confirms that looking for a specific attribute in just one way might be misleading. Local context is 
nonetheless clearly implicated in the territorial distribution of overweight, but a variety of information suggests that interventions aiming at overweight management might need to differ between genders as well as between regions. We consequently recommend research that seeks to understand local and regional idiosyncrasies according to the socioeconomic built environment, and more specifically the foodscape, while accounting for mobility patterns, prior to implementing more-or-less generic interventions at the local level. A more in-depth study accounting for the interaction between individuals and local areas' characteristics might also be a promising avenue for increasing our understanding of the embodiment of environmental influences and how they get, in the end, under the skin [39].

\section{References}

[1] WHO, Preventing and Managing the Global Epidemic, WHO, Geneva, Switzerland, 2000.

[2] K. R. Fontaine, D. T. Redden, C. Wang, A. O. Westfall, and D. B. Allison, "Years of life lost due to obesity," Journal of the American Medical Association, vol. 289, no. 2, pp. 187-193, 2003.

[3] R. L. Weinsier, G. R. Hunter, A. F. Heini, M. I. Goran, and S. M. Sell, "The etiology of obesity: relative contribution of metabolic factors, diet, and physical activity," American Journal of Medicine, vol. 105, no. 2, pp. 145-150, 1998.

[4] T. T. Huang, A. Drewnosksi, S. K. Kumanyika, and T. A. Glass, "A systems-oriented multilevel framework for addressing obesity in the 21st century," Preventing Chronic Disease, vol. 6, no. 3, pp. 1-10, Public Health Research, Practice and Policy, 2009.

[5] S. Srinivasan, L. R. O’Fallon, and A. Dearry, "Creating healthy communities, healthy homes, healthy people: initiating a research agenda on the built environment and public health," American Journal of Public Health, vol. 93, no. 9, pp. 14461450, 2003.

[6] S. J. Olshansky, D. J. Passaro, R. C. Hershow et al., "A potential decline in life expectancy in the United States in the 21st century," New England Journal of Medicine, vol. 352, no. 11, pp. 1138-1145, 2005.

[7] L. McLaren, "Socioeconomic status and obesity," Epidemiologic Reviews, vol. 29, no. 1, pp. 29-48, 2007.

[8] K. M. Booth, M. M. Pinkston, and W. S. Poston, "Obesity and the built environment," Journal of the American Dietetic Association, vol. 105, no. 5, pp. S110-S117, 2005.

[9] M. A. Papas, A. J. Alberg, R. Ewing, K. J. Helzlsouer, T. L. Gary, and A. C. Klassen, "The built environment and obesity," Epidemiologic Reviews, vol. 29, no. 1, pp. 129-143, 2007.

[10] L. Franzini, M. N. Elliott, P. Cuccaro et al., "Influences of physical and social neighborhood environments on children's physical activity and obesity," American Journal of Public Health, vol. 99, no. 2, pp. 271-278, 2009.

[11] G. Moon, G. Quarendon, S. Barnard, L. Twigg, and B. Blyth, "Fat nation: deciphering the distinctive geographies of obesity in England," Social Science and Medicine, vol. 65, no. 1, pp. 2031, 2007.

[12] S. Cummins and S. Macintyre, "Food environments and obesity—neighbourhood or nation?" International Journal of Epidemiology, vol. 35, no. 1, pp. 100-104, 2006.

[13] J. L. Black and J. Macinko, "Neighborhoods and obesity," Nutrition Reviews, vol. 66, no. 1, pp. 2-20, 2008.
[14] A. Michimi and M. C. Wimberly, "Spatial patterns of obesity and associated risk factors in the conterminous U.S," American Journal of Preventive Medicine, vol. 39, no. 2, pp. e1-e12, 2010.

[15] J. Feng, T. A. Glass, F. C. Curriero, W. F. Stewart, and B. S. Schwartz, "The built environment and obesity: a systematic review of the epidemiologic evidence," Health and Place, vol. 16, no. 2, pp. 175-190, 2010.

[16] K. M. Booth, M. M. Pinkston, and W. S. C. Poston, "Obesity and the built environment," Journal of the American Dietetic Association, vol. 105, no. 5, pp. S110-S117, 2005.

[17] R. A. McKinnon, J. Reedy, M. A. Morrissette, L. A. Lytle, and A. L. Yaroch, "Measures of the Food Environment. A Compilation of the Literature, 1990-2007," American Journal of Preventive Medicine, vol. 36, no. 4, pp. S124-S133, 2009.

[18] Y. Kestens, A. Lebel, M. Daniel, M. Thériault, and R. Pampalon, "Using experienced activity spaces to measure foodscape exposure," Health and Place, vol. 16, no. 6, pp. 1094-1103, 2010.

[19] B. Chaix, "Geographic life environments and coronary heart disease: a literature review, theoretical contributions, methodological updates, and a research agenda," Annual Review of Public Health, vol. 30, pp. 81-105, 2009.

[20] S. Cummins, "Commentary: investigating neighbourhood effects on health-avoiding the "local trap"', International Journal of Epidemiology, vol. 36, no. 2, pp. 355-357, 2007.

[21] A. Lebel, R. Pampalon, M. Thériault, and D. Hamel, "The geography of overweight in Quebec: a multilevel perspective," Canadian Journal of Public Health, vol. 100, no. 1, pp. 18-23, 2009.

[22] A. Lebel, M. Riva, R. Pampalon, and M. Thériault, "The geography of overweight in Quebec: analyzing and visualizing spatial inequalities using second-level residuals," Canadian Journal of Public Health, vol. 101, no. 2, pp. 133-137, 2010.

[23] L. Gauvin, L. Richard, C. L. Craig et al., "From walkability to active living potential: an "ecometric" validation study," American Journal of Preventive Medicine, vol. 28, no. 2, pp. 126-133, 2005.

[24] Commission D'aménagement de la Communauté Urbaine de Québec: Schéma d'aménagement, Première Phase, Études Sectorielles, Québec, Canada, 1972.

[25] M. Thériault, M. Voisin, and F. des Rosiers, "L'accessibilité aux services urbains: modélisation des différences socio-spatiales et mesure des impacts sur les valeurs résidentielles," in Information Géographique et Dynamiques Urbaines, M. Thériault and F. des Rosiers, Eds., pp. 119-151, London, UK, 2008.

[26] A. Lebel, R. Pampalon, and P. Y. Villeneuve, "A multiperspective approach for defining neighbourhood units in the context of a study on health inequalities in the Quebec City region," International Journal of Health Geographics, vol. 6, article 27, 2007.

[27] N. Goulet, S. Lavoie, and S. A. K. Azzou, Un Nouveau Découpage Territorial à Montréal: Les Voisinages, Adence de la Santé et des Services Sociaux de Montréal, Montréal, QC, Canada, 2009.

[28] "Statistics Canada: Canadian Community Health Survey," http://www.statcan.gc.ca/cgi-bin/imdb/p2SV.pl?Function= getSurvey $\&$ SDDS $=3226 \&$ lang $=\mathrm{en} \& \mathrm{db}=\mathrm{imdb} \& \mathrm{adm}=8 \& \mathrm{dis}=$ 2\#a4, 2011.

[29] R. Pampalon and G. Raymond, "A deprivation index for health and welfare planning in Quebec," Chronic Diseases in Canada, vol. 21, no. 3, pp. 104-113, 2000.

[30] A. Diez Roux, "A glossary for multilevel analysis," Journal of Epidemiology and Community Health, vol. 56, no. 8, pp. 588594, 2002. 
[31] J. Merlo, B. Chaix, H. Ohlsson et al., "A brief conceptual tutorial of multilevel analysis in social epidemiology: using measures of clustering in multilevel logistic regression to investigate contextual phenomena," Journal of Epidemiology and Community Health, vol. 60, no. 4, pp. 290-297, 2006.

[32] N. A. Ross, S. Tremblay, S. Khan, D. Crouse, M. Tremblay, and J.-M. Berthelot, "Body mass index in urban Canada: neighborhood and metropolitan area effects," American Journal of Public Health, vol. 97, no. 3, pp. 500-508, 2007.

[33] N. Schuurman, N. Bell, J. R. Dunn, and L. Oliver, "Deprivation indices, population health and geography: an evaluation of the spatial effectiveness of indices at multiple scales," Journal of Urban Health, vol. 84, no. 4, pp. 591-603, 2007.

[34] A. Lebel, R. Pampalon, and M. St-Hilaire, "Le repérage des unités de voisinage. Contribution d'une approche historique en milieu urbain, périurbain et rural dans la région de Québec," Cahiers de Geographie du Quebec, vol. 49, no. 137, pp. 191-206, 2005.

[35] D. P. Do, T. Dubowitz, C. E. Bird, N. Lurie, J. J. Escarce, and B. K. Finch, "Neighborhood context and ethnicity differences in body mass index: a multilevel analysis using the NHANES III survey (1988-1994)," Economics and Human Biology, vol. 5, no. 2, pp. 179-203, 2007.

[36] S. A. Robert and E. N. Reither, "A multilevel analysis of race, community disadvantage, and body mass index among adults in the US," Social Science and Medicine, vol. 59, no. 12, pp. 2421-2434, 2004

[37] M. Tjepkema, Obésité Chez les Adultes au Canada: Poids et Grandeur Mesurés, Statistique Canada Publications, 2005.

[38] M. Shields, S. C. Connor Gorber, and S. Tremblay, Estimates of Obesity Based on Self-Report Versus Direct Measures, Statistique Canada, Ottawa, Canada, 2008.

[39] N. Krieger, "Embodiment: a conceptual glossary for epidemiology," Journal of Epidemiology and Community Health, vol. 59, no. 5, pp. 350-355, 2005. 


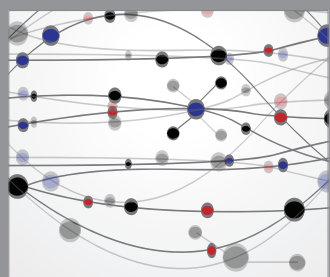

The Scientific World Journal
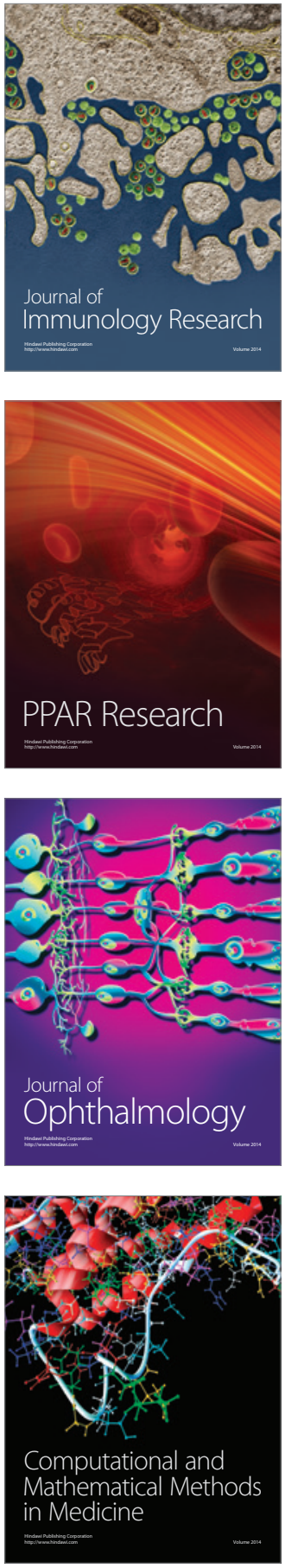

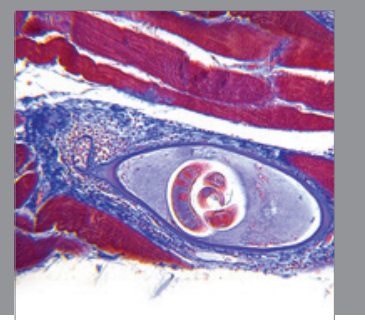

Gastroenterology

Research and Practice
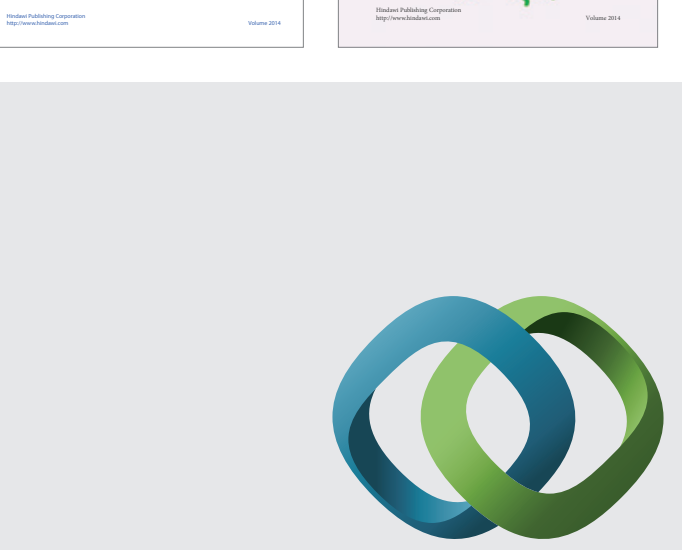

\section{Hindawi}

Submit your manuscripts at

http://www.hindawi.com
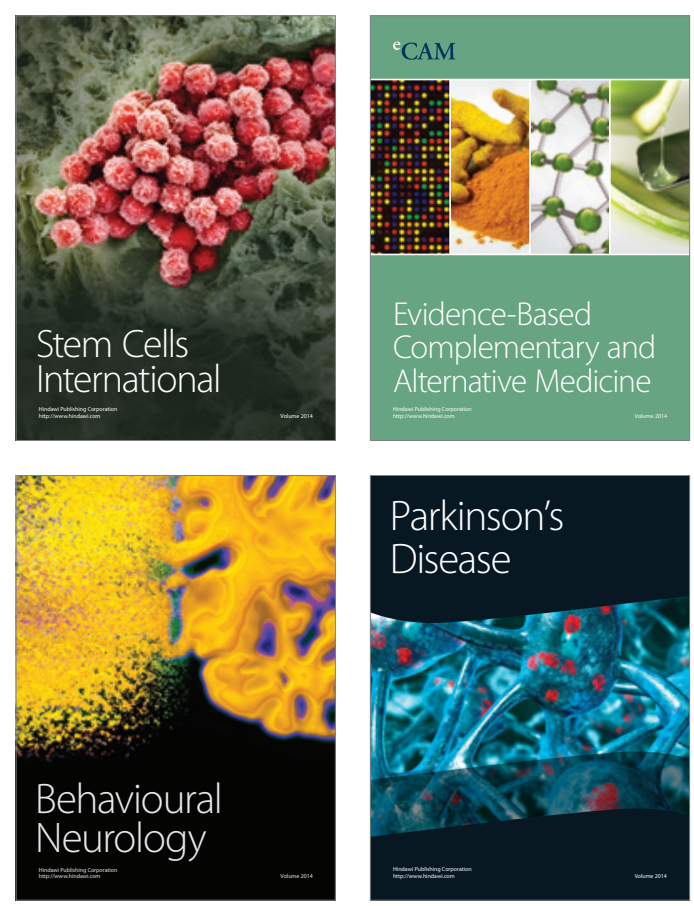

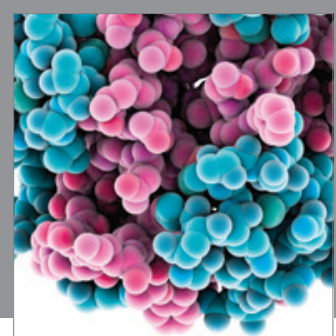

Journal of
Diabetes Research

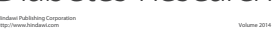

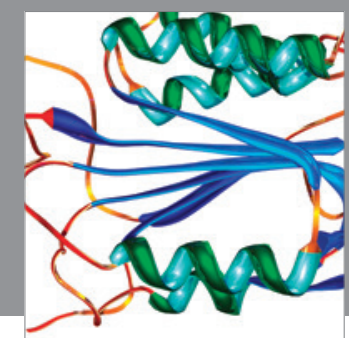

Disease Markers
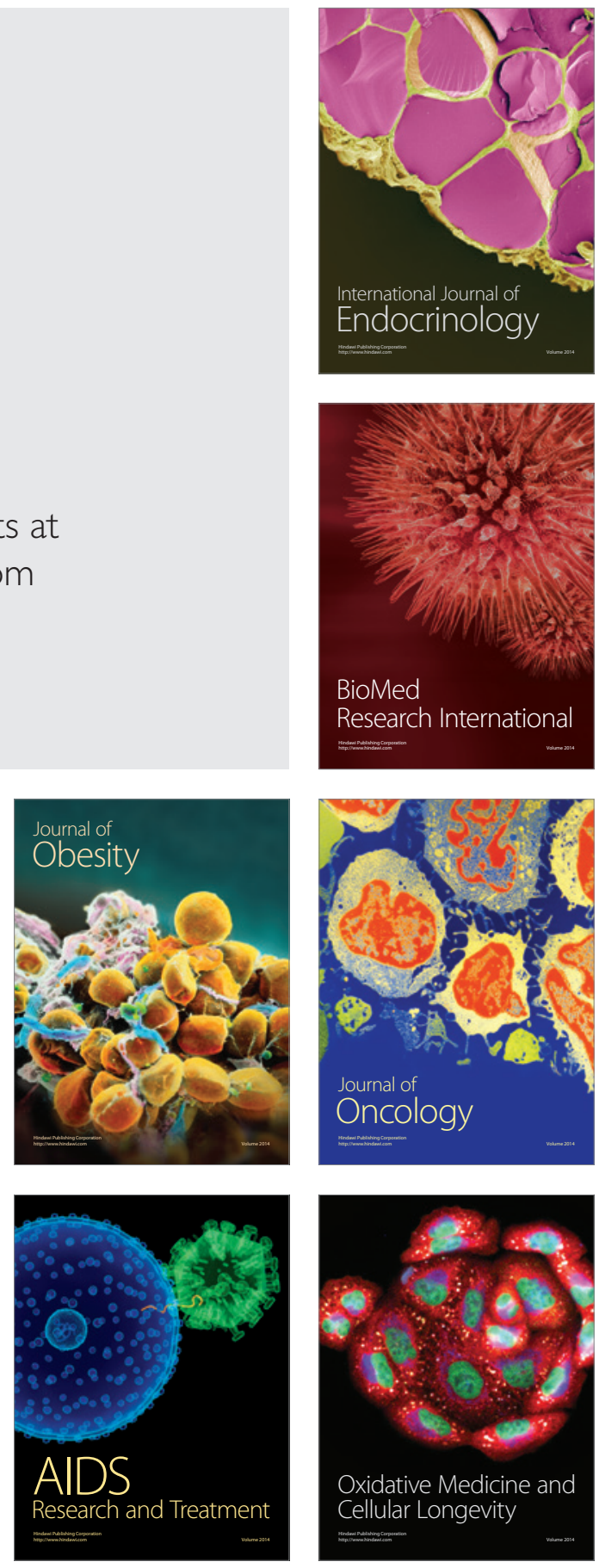